RESEARCH REPORT

\title{
Effect of social exclusion on the risk of teenage pregnancy: development of hypotheses using baseline data from a randomised trial of sex education
}

\author{
C P Bonell, V J Strange, J M Stephenson, A R Oakley, A J Copas, S P Forrest, A M Johnson, S Black
}

J Epidemiol Community Health 2003;57:871-876

See end of article for authors' affiliations

Correspondence to: MsV J Strange, Social Science Research Unit, Institute of Education, University of London, 18 Woburn Square, London WCIH ONR, UK; v.strange@ioe.ac.uk

Accepted for publication 21 April 2003

\begin{abstract}
Study objective: The UK government argues that "social exclusion" increases risk of teenage pregnancy and that educational factors may be dimensions of such exclusion. The evidence cited by the government is limited to reporting that socioeconomic disadvantage and educational attainment influence risk. Evidence regarding young people's attitude to school is not cited, and there is a lack of research concerning the UK. This paper develops hypotheses on the relation between socioeconomic and educational dimensions of social exclusion, and risk of teenage pregnancy, by examining whether dislike of school and socioeconomic disadvantage are associated with cognitive/behavioural risk measures among 13/14 year olds in English schools.

Design: Analysis of data from the baseline survey of a study of sex education.

Setting and participants: 13/14 year old school students from south east England.

Main results: The results indicate that socioeconomic disadvantage and dislike of school are associated with various risk factors, each with a different pattern. Those disliking school, despite having comparable knowledge to those liking school, were more likely to have sexual intercourse, expect sexual intercourse by age 16, and expect to be parents by the age of 20. For most associations, the crude odds ratios (ORs) and the ORs adjusted for the other exposure were similar, suggesting that inter-confounding between exposures was limited.

Conclusions: It is hypothesised that in determining risk of teenage pregnancy, the two exposures are independent. Those disliking school might be at greater risk of teenage pregnancy because they are more likely to see teenage pregnancy as inevitable or positive.
\end{abstract}

T e UK government has identified social exclusion as a key determinant of teenage pregnancy. Social exclusion ${ }^{1}$ entails individuals being disadvantaged not just economically but also in terms of other dimensions such as education, citizenship, and cultural resources. ${ }^{23}$ The term social exclusion is also intended to draw attention to a process of accumulating disadvantage where different factors are pivotal at different points in people's lives. ${ }^{4}$

In the UK government's strategy for reducing teenage pregnancy, ${ }^{5}$ risk factors for teenage pregnancy are identified. Some, such as low socioeconomic status, encapsulate economic dimensions of social exclusion. Others, such as negative attitudes to school and low expectations about future education and employment, focus on educational dimensions of social exclusion.

The strategy cites evidence to support its assertion that economic disadvantage is a determinant of teenage parenthood. ${ }^{6}$ The strategy also cites evidence from Kiernan ${ }^{7}$ and Include $^{8}$ that young people in the UK with low educational attainment or who are excluded from school are at greater risk of teenage parenthood. The strategy does not however cite evidence concerning another dimension of educational disadvantage: dissatisfaction with school.

\section{Existing research on attitudes to education and risk of} teenage pregnancy

Is dislike of school an important determinant of teenage pregnancy? To explore this question we first systematically reviewed existing quantitative research on the association between young people's attitudes to school and teenage pregnancy. We used a search strategy that comprehensively identified post-1991 published studies examining educational attitudes, attendance, and attainment on pregnancy and other sexual health outcomes of teenagers and other young people, present on Medline and Embase. Two US studies have examined associations between dissatisfaction with school and risk of various sexual health outcomes. Dearden et al found an association between teenage fatherhood and disliking school, $(\mathrm{OR}=3.2,95 \%$ confidence intervals 2.1 to 4.8$).{ }^{9}$ Mott et al reported no association between boredom with school and sex by age $14 .{ }^{10}$ Paul et al report an association among young people from New Zealand between positive attitude to school and sex by age 16 for boys, with an OR of 0.10 (95\% confidence intervals of 0.03 to $0.3) .{ }^{11}$ There was no association between attitude to school and sex by age 16 for girls.

We also reviewed relevant qualitative research. A qualitative study from the UK reports that lack of interest in, and expectations about, education and subsequent employment might affect risk of teenage pregnancy. ${ }^{12}$ A lack of educational aspirations among some, but not all, young women from disadvantaged backgrounds engendered a sense of fatalism, making it difficult for them to make real choices about sex and parenthood. For other young women, the lack of alternative aspirations informed a view that teenage parenthood might not be disruptive, and indeed might be a positive choice. This research involved a small sample and did not attempt to generate statistically significant findings.

In summary therefore, existing quantitative studies show mixed results, and are not directly pertinent to contemporary UK society, while qualitative data cannot provide generalisable evidence. 


\section{Study aims}

This study attempted to develop hypotheses concerning the effect of differing aspects of social exclusion on young people's risk of teenage pregnancy. It did so by examining the social circumstances, cognitions and behaviour of UK school students aged 13 and 14 . We explored whether two dimensions of social exclusion-socioeconomic disadvantage and dislike of school-are each associated with cognitions and behaviours, which may predict risk of future teenage parenthood. The study aimed to develop hypotheses concerning causality, which will be tested in later longitudinal analyses of data from the same study.

\section{METHODS}

\section{Data collection}

We analysed data arising from a baseline survey of mixed sex state secondary school year 9 students (aged 13 and 14) within a cluster randomised controlled trial of peer led sex education. Twenty seven schools in central and southern England entered the study in the spring and summer of 1997. Details of the study, which is still in progress, have been published elsewhere. ${ }^{13}$ Questionnaires were designed in consultation with students, extensively piloted and addressed demography, sexual knowledge, attitudes and behaviour, other behaviours, and views on school and sex education. ${ }^{14}$ In these baseline questionnaires "sex" was defined as heterosexual sexual intercourse. Students completed the questionnaires in lesson time. Permission was sought from all parents/carers to include their children in the study. The study was approved by University College London committees on the ethics of human research.

\section{Data analysis}

Two items were pre-hypothesised as "exposures", these focusing on various possible dimensions of social exclusion. Firstly, socioeconomic status was measured via self reported housing tenure. Students reporting that they lived in nonprivately owned housing were defined as "disadvantaged". Data from this question were more complete than for questions about parental occupation. In addition, it has been argued that this may be a more valid measure of socioeconomic status for people other than adult men. ${ }^{14}$ Secondly, attitude to school was measured with the statement "I like school". Students who disagreed or strongly disagreed with this statement were defined as "disliking school", those who neither agreed or disagreed were defined as being "ambivalent".

Various items were pre-hypothesised as outcome measures, these being possible predictors of subsequent risk of teenage parenthood (see discussion below). Knowledge about sex and contraception was indicated by 13 questions about contraception and safer sex. Students not answering correctly at least 7 of 13 questions (all with equal weighting) were considered to have low knowledge. Those who missed more than one questions were excluded. Confidence about condom use was indicated by a question asking how easy or difficult it would be to use a condom properly. Low confidence about condom use was indicated by viewing condom use as "difficult" or "very difficult", or being "unsure" about this. Antipathy to condoms was indicated by students' being ambivalent, disagreeing or strongly disagreeing that using a condom would be a smart thing to do. A belief that peers are having sex was based on responding that half or more of one's same sex peers have had sex. An expectation that the young person will have sexual intercourse by age 16 was indicated by a positive response to a direct question on this matter. An expectation that the young person will be a parent by age 20 was indicated by the young person responding that this was likely or very likely, and those who where unsure were removed from the analysis of association with the two exposures.

Self reported behaviour was also explored. Regularly being drunk was indicated by respondents reporting they have been drunk once a month or more. Sexual activity was indicated by self reported experience of having had sex. In addition some students were reclassified as not having had sex where later questionnaire responses indicated they had never had sex, and some of those students who omitted the question could be re-classified using the age at first sex provided in later questionnaires. Sex in itself, rather than use of condoms in sex, was focused on principally because the proportion of the sample having had sex meant that an examination of the latter outcome would be statistically underpowered. Analysis of young people's expectations about whether they would have sex by age 16 included only those who had not already had sex, as actual experience of sex was examined separately. Associations between the outcomes and, in turn, housing tenure and attitude to school, stratified by gender were examined. Interactions betweens the effect on outcomes of the two exposures were then explored. Odds ratios generated in logistic regression are reported. All analysis took account of clustering of participants within schools, using the survey analysis functions of Stata 6.

\section{RESULTS}

A total of 9691 students were enrolled in year 9 in the 27 schools in 1997 and 1998. One hundred and eighty three were withdrawn from the study by their parents. Of those eligible, 8766 (92\%) completed baseline questionnaires; 4248 (48\%) were girls and 4518 (52\%) were boys. Ninety one per cent described themselves as "white" and 9\% as Indian, Pakistani, Bangladeshi, Black African, Black Caribbean, Chinese, or other. The mean age was 13 years and 8 months (13.69, SD 0.32).

Data describing the sample in terms of exposure and outcome measures are reported in table 1. Just over one quarter of boys and girls lived in non owner-occupier housing and so is classified for the purposes of this study as socioeconomically disadvantaged. While $23.2 \%$ of boys disliked or strongly disliked school, only $15.4 \%$ of girls did so. Knowledge of sex and contraception was low: around half of boys and girls could not answer seven or more questions correctly. Lack of confidence or uncertainty about condom use was much greater among girls (64.0\%) than boys (35.4\%). About $10 \%$ of girls and $14 \%$ of boys did not agree or strongly agree with a statement that use of condoms was a smart thing to do, and were thus classified as antipathetic to condom use. About $8 \%$ of both boys and girls thought half or more of their gender and age peers were sexually active. Nearly half of students who answered the relevant question thought it likely or very likely they would be sexually active by age 16 . More boys (20.7\%) than girls (15.5\%) thought they would be likely or very likely to become teenage parents. In terms of behaviour, about $13 \%$ of both boys and girls reported being drunk monthly or more, and $6.7 \%$ of boys and girls reported already having sex.

Table 2 reports on the associations between each of the two exposures. Among the overall sample, only $6.7 \%$ were socioeconomically disadvantaged and disliked school, while $34.2 \%$ of the sample either was socioeconomically disadvantaged or disliked school but not both. This pattern was similar for boys and girls when analysed separately.

Tables 3 and 4 report on the associations between, respectively, socioeconomic status (as indicated by housing tenure), and attitude to school and each of our prehypothesised outcomes, stratified by gender. Each table reports crude ORs (with 95\% confidence intervals) and ORs for associations adjusted for the other exposure. In summary, 
Table 1 Description of the sample in terms of key measures

\begin{tabular}{|c|c|c|c|}
\hline \multirow[b]{2}{*}{ Measure } & \multicolumn{3}{|l|}{ Frequency* } \\
\hline & Among girls(\%) & Among boys $(\%)$ & Overall (\%) \\
\hline \multicolumn{4}{|l|}{ Housing tenure $\dagger$} \\
\hline Council rented & $803 / 3673$ (21.9) & $857 / 3863(22.2)$ & $1660 / 7536(22.0)$ \\
\hline Other rented & $203 / 3673(5.5)$ & $193 / 3863(5.0)$ & $396 / 7536(5.3)$ \\
\hline Privately owned & $2625 / 3673(71.5)$ & $2768 / 3863(71.7)$ & $5393 / 7536(71.6)$ \\
\hline Temporary & $28 / 3673(0.8)$ & $34 / 3863(0.9)$ & $62 / 7536(0.8)$ \\
\hline Care/foster home & $14 / 3673(0.4)$ & $11 / 3863(0.3)$ & $25 / 7536(0.3)$ \\
\hline \multicolumn{4}{|l|}{ Attitude to school } \\
\hline Likes school & $2141 / 4230(50.6)$ & $1879 / 4455(42.2)$ & $4020 / 8685(46.3)$ \\
\hline Ambivalent & $1437 / 4230(34.0)$ & $1543 / 4455(34.6)$ & $2980 / 8685$ (34.3) \\
\hline Dislikes school & $652 / 4230(15.4)$ & $1033 / 4455(23.2)$ & $1685 / 8685(19.4)$ \\
\hline \multicolumn{4}{|c|}{ Knowledge about contraception and STIs } \\
\hline Low & $1558 / 3642(42.8)$ & $1931 / 3622(53.3)$ & $3489 / 7264(48.0)$ \\
\hline High & $2084 / 3642(57.2)$ & $1691 / 3622(46.7)$ & $3775 / 7264(52.0)$ \\
\hline \multicolumn{4}{|c|}{ Confidence about condom use } \\
\hline High & $1465 / 4060(36.0)$ & $2718 / 4207(64.6)$ & $4183 / 4727(50.6)$ \\
\hline Unsure & $2220 / 4060(54.7)$ & $1320 / 4207(31.4)$ & $3540 / 8267(42.8)$ \\
\hline Low & $375 / 4060$ (9.2) & $169 / 4207(4.0)$ & $544 / 8267(6.6)$ \\
\hline \multicolumn{4}{|c|}{ Attitude towards condom use } \\
\hline Positive & $3563 / 3968(89.8)$ & $3474 / 4031(86.2)$ & $7037 / 7999(88.0)$ \\
\hline Ambivalent & $273 / 3968(6.9)$ & $380 / 4031(9.4)$ & $653 / 7999(8.2)$ \\
\hline Negative & $132 / 3968$ (3.3) & $177 / 4031(4.4)$ & $309 / 7999$ (3.9) \\
\hline \multicolumn{4}{|c|}{ Beliefs about peers (same age and gender) having sex } \\
\hline Less than half & $3486 / 3795$ (91.9) & $3648 / 3957(92.2)$ & $7134 / 7752(92.0)$ \\
\hline Half or more & $309 / 3795(8.1)$ & $309 / 3957(7.8)$ & $618 / 7752(8.0)$ \\
\hline \multicolumn{4}{|c|}{ Age at which expect to have sexual intercourse if not happened already } \\
\hline By age 16 & $1340 / 2962(45.2)$ & $1582 / 3337(47.3)$ & $2922 / 6299(46.4)$ \\
\hline By age 17-19 & $1083 / 2962(36.6)$ & $1169 / 3337(35.0)$ & $2252 / 6299(35.8)$ \\
\hline When 20 or older & $527 / 2962(17.8)$ & $565 / 3337(16.9)$ & $1092 / 6299(17.3)$ \\
\hline Never & $12 / 2962(0.4)$ & $23 / 3337(0.7)$ & $35 / 6299(0.6)$ \\
\hline \multicolumn{4}{|c|}{ Expectations of parenthood by age 20} \\
\hline Very/quite likely & $650 / 4206(15.5)$ & $916 / 4434(20.7)$ & $1566 / 8640(18.1)$ \\
\hline Unsure & $1203 / 4206(28.6)$ & $1497 / 4434(33.8)$ & $2700 / 8640$ (31.3) \\
\hline Unlikely/very unlikely & $2353 / 4206(56.0)$ & $2021 / 4434(45.6)$ & $4374 / 8640$ (50.6) \\
\hline \multicolumn{4}{|l|}{ Been drunk ${ }^{\star *}$} \\
\hline Never & $2430 / 4080(59.6)$ & $2472 / 4269$ (57.9) & $4902 / 8349$ (58.7) \\
\hline Once or twice a year & $1102 / 4080$ (27.0) & $1224 / 4269(28.7)$ & $2326 / 8349$ (27.9) \\
\hline \multicolumn{4}{|l|}{$\begin{array}{l}\text { Unce a month or more } \\
\text { Had sexual intercourse }\end{array}$} \\
\hline Yes & $276 / 4124(6.7)$ & $290 / 4352(6.7)$ & $566 / 8476(6.7)$ \\
\hline No & $3848 / 4124$ (93.3) & $4062 / 4352$ (93.3) & $7910 / 8476$ (93.3) \\
\hline
\end{tabular}

our various hypothesised dimensions of social exclusion were subject to a number of associations, as follows.

(1) Among boys and girls, socioeconomic disadvantage was significantly and independently associated with: low knowledge about sex and contraception (adjusted OR, girls 1.81 (CI 1.45 to 2.27 ), boys 1.48 (CI 1.22 to 1.80 )); negative or ambivalent attitudes to condom use ( 1.82 (CI 1.39 to 2.38 ), 1.51 (CI 1.15 to 2.00)); a belief that most peers are already having sex (2.00 (CI 1.52 to 2.65), 1.88 (CI 1.39 to 2.56)); an expectation of being a parent by age 20 (2.34 (CI 1.87 to $2.93), 1.91$ (1.53 to 2.39)), and having sexual intercourse ( 1.44 (CI 1.08 to 1.93 ), 1.89 (CI 1.38 to 2.59 )). Socioeconomic

Table 2 Overlap of exposures

\begin{tabular}{|c|c|c|c|c|c|c|}
\hline & & & \multicolumn{3}{|c|}{ Attitude to school } & \multirow{2}{*}{$\begin{array}{l}\chi^{2} \text { Test for } \\
\text { association }\end{array}$} \\
\hline & & & Like school & Ambivalent & Dislike school & \\
\hline \multirow[t]{3}{*}{$\begin{array}{l}\text { Housing } \\
\text { tenure }\end{array}$} & Girls & $\begin{array}{l}\text { Not privately } \\
\text { owned }(\%) \\
\text { Privately } \\
\text { owned (\%) }\end{array}$ & $\begin{array}{l}477 / 3669 \\
(13.0) \\
1412 / 3669 \\
(38.5)\end{array}$ & $\begin{array}{l}359 / 3669 \\
(9.8) \\
859 / 3669 \\
(23.4)\end{array}$ & $\begin{array}{l}211 / 3669 \\
(5.8) \\
351 / 3669 \\
(9.7)\end{array}$ & $p<0.001$ \\
\hline & Boys & $\begin{array}{l}\text { Not privately } \\
\text { owned }(\%) \\
\text { Privately } \\
\text { owned (\%) }\end{array}$ & $\begin{array}{l}410 / 3826 \\
(10.7) \\
1203 / 3826 \\
(31.4)\end{array}$ & $\begin{array}{l}383 / 3826 \\
(10.0) \\
954 / 3826 \\
(24.9)\end{array}$ & $\begin{array}{l}292 / 3826 \\
(7.6) \\
584 / 3826 \\
(15.3)\end{array}$ & $p<0.01$ \\
\hline & All & $\begin{array}{l}\text { Not privately } \\
\text { owned }(\%) \\
\text { Privately } \\
\text { owned }(\%)\end{array}$ & $\begin{array}{l}887 / 7495 \\
(11.9) \\
2615 / 7495 \\
(34.9)\end{array}$ & $\begin{array}{l}742 / 7495 \\
(9.9) \\
1813 / 7495 \\
(24.2)\end{array}$ & $\begin{array}{l}503 / 7495 \\
(6.7) \\
935 / 7495 \\
(12.5)\end{array}$ & $p<0.001$ \\
\hline
\end{tabular}


Table 3 Housing tenure and outcomes

\begin{tabular}{|c|c|c|c|c|c|c|}
\hline & \multicolumn{2}{|c|}{ Frequency of outcome $(\%)$} & \multicolumn{2}{|l|}{ Crude OR $(95 \% \mathrm{Cl})$} & \multicolumn{2}{|c|}{ OR adjusted for attitude towards school $(95 \% \mathrm{Cl})$} \\
\hline & Girls & Boys & Girls & Boys & Girls & Boys \\
\hline \multicolumn{7}{|c|}{ Low knowledge of contraception and STIs? } \\
\hline Privately owned (\%) & $824 / 2272(36.3)$ & $1072 / 2238$ (47.9) & 1 & 1 & 1 & 1 \\
\hline Not privately owned ( & $456 / 899(50.7)$ & $502 / 869(57.8)$ & 1.82 (148 to 2.24 ) & 1.48 (1.24 to 1.79$)$ & 1.81 (1.45 to 2.27$)$ & $1.48(1.22$ to 1.80$)$ \\
\hline \multicolumn{7}{|c|}{ Low or unsure condom confidence } \\
\hline Privately owned (\%) & $1632 / 2534(64.4)$ & $877 / 2621(33.5)$ & 1 & 1 & 1 & 1 \\
\hline Not privately owned 19 & 6) $589 / 996(59.1)$ & $351 / 1006(34.9)$ & 0.80 (0.69 to 0.93$)$ & $1.07(0.89$ to 1.28$)$ & $0.81(0.70$ to 0.95$)$ & $1.08(0.90$ to 1.31$)$ \\
\hline \multicolumn{7}{|c|}{ Negative or ambivalent attitude towards condom use } \\
\hline Privately owned (\%) & $202 / 2510(8.1)$ & $299 / 2526(11.8)$ & 1 & 1 & 1 & 1 \\
\hline Not privately owned ( & 6) $134 / 966$ (13.9) & $162 / 950(17.1)$ & 1.84 (1.41 to 2.40$)$ & 1.53 (1.16 to 2.02$)$ & 1.82 (1.39 to 2.38$)$ & 1.51 (1.15 to 2.00$)$ \\
\hline \multicolumn{7}{|c|}{ Believes most peers have sexual intercourse } \\
\hline Privately owned (\%) & $143 / 2362(6.5)$ & $157 / 2454(6.4)$ & 1 & 1 & 1 & 1 \\
\hline Not privately owned 19 & 6) $117 / 948$ (12.3) & $113 / 957(11.8)$ & 2.18 (1.66 to 2.88 ) & $1.96(1.47$ to 2.60$)$ & $2.00(1.52$ to 2.65$)$ & 1.88 (1.39 to 2.56$)$ \\
\hline \multicolumn{7}{|c|}{ Expects sex by aged $16^{*}$} \\
\hline Privately owned (\%) & $876 / 1854(47.3)$ & $1039 / 2112(49.2)$ & 1 & 1 & 1 & 1 \\
\hline Not privately owned 19 & 6) $327 / 727$ (45.0) & $359 / 774(46.4)$ & 0.91 (0.78 to 1.07$)$ & $0.89(0.75$ to 1.06$)$ & 0.87 (0.74 to 1.02$)$ & $0.86(0.72$ to 1.02$)$ \\
\hline \multicolumn{7}{|c|}{ Expects parenthood by aged $20^{*}$} \\
\hline Privately owned (\%) & $308 / 1915(16.1)$ & $495 / 1867(26.5)$ & 1 & 1 & 1 & 1 \\
\hline Not privately owned 19 & 6) $227 / 703$ (32.3) & $291 / 702(41.5)$ & 2.49 (2.02 to 3.07$)$ & 1.96 (1.56 to 2.46$)$ & 2.34 (1.87 to 2.93$)$ & 1.91 (1.53 to 2.39 ) \\
\hline \multicolumn{7}{|c|}{ Drunk once a month or more } \\
\hline Privately owned (\%) & $313 / 2533(12.4)$ & $356 / 2613(13.6)$ & 1 & 1 & 1 & 1 \\
\hline \multicolumn{4}{|c|}{ Had sexual intercourse } & 1.04 (0.81 to 1.34$)$ & $1.38(1.10$ to 1.74$)$ & $0.97(0.75$ to 1.26$)$ \\
\hline Privately owned (\%) & $151 / 2567(5.9)$ & $144 / 2688(5.4)$ & 1 & 1 & 1 & 1 \\
\hline Not privately owned ( & 6) $92 / 1012(9.1)$ & $104 / 1045(10.0)$ & 1.60 (1.22 to 2.1$)$ & 1.95 (1.43 to 2.66$)$ & $1.44(1.08$ to 1.93$)$ & 1.89 (1.38 to 2.59$)$ \\
\hline
\end{tabular}

disadvantage was also associated with higher confidence regarding condom use (0.81 (0.70 to 0.95)) and being drunk monthly or more ( 1.38 (CI 1.10 to 1.74$)$ ) among girls but not boys.

(2) Among both boys and girls, dislike of school was significantly and independently associated with believing most peers to be having sex (girls 2.80 (2.10 to 3.72), boys 2.07 ( 1.35 to 3.19$)$ ), expecting to have sex by age 16 ( 1.68 ( 1.33 to 2.10$), 1.98$ ( 1.55 to 2.54$)$ ), expecting to be a parent by age 20 (2.33 ( 1.79 to 3.04$)$, 1.41 ( 1.14 to 1.75$))$, having been drunk monthly or more (3.79 (2.92 to 4.92$), 3.77$ (2.81 to $5.07)$ ), and having sexual intercourse (3.74 (2.40 to 5.81$)$,

Table 4 Attitude to school and outcomes

\begin{tabular}{|c|c|c|c|c|c|c|}
\hline & \multicolumn{2}{|c|}{ Frequency of outcomes (\%) } & \multicolumn{2}{|l|}{ Crude OR $(95 \% \mathrm{CI})$} & \multicolumn{2}{|c|}{ OR adjusted for housing $(95 \% \mathrm{Cl})$} \\
\hline & Girls & Boys & Girls & Boys & Girls & Boys \\
\hline \multicolumn{7}{|c|}{ Low knowledge of contraception and STls } \\
\hline Like school & $772 / 1834(42.1)$ & $821 / 1512$ (54.3) & 1 & 1 & 1 & 1 \\
\hline Ambivalent & $539 / 1235(43.6)$ & $655 / 1248(52.5)$ & $1.06(0.90$ to 1.27$)$ & $0.93(0.78$ to 1.11$)$ & $1.03(0.86$ to 1.24$)$ & $0.98(0.81$ to 1.18$)$ \\
\hline Dislike school & $243 / 567(42.9)$ & $442 / 840(52.6)$ & 1.03 (0.83 to 1.28$)$ & $0.93(0.78$ to 1.13$)$ & $0.96(0.78$ to 1.19$)$ & $0.90(0.74$ to 1.09$)$ \\
\hline \multicolumn{7}{|c|}{ Low or unsure condom confidence } \\
\hline Like school & $1328 / 2054(64.6)$ & $664 / 1768(37.6)$ & 1 & 1 & 1 & 1 \\
\hline Ambivalent & $898 / 1378(65.2)$ & $507 / 1440(35.2)$ & $1.02(0.90$ to 1.17$)$ & $0.90(0.77$ to 1.07$)$ & $0.98(0.85$ to 1.14$)$ & $0.94(0.78$ to 1.14$)$ \\
\hline Dislike school & $362 / 621(58.3)$ & $305 / 967(31.5)$ & $0.76(0.62$ to 0.94$)$ & $0.77(0.66$ to 0.90$)$ & $0.77(0.62$ to 0.95$)$ & $0.77(0.64$ to 0.92$)$ \\
\hline \multicolumn{7}{|c|}{ Negative or ambivalent attitude towards condom use } \\
\hline Like school & $196 / 2017(9.7)$ & $221 / 1700(13.0)$ & 1 & 1 & 1 & 1 \\
\hline Ambivalent & $139 / 1345(10.3)$ & $192 / 1396(13.8)$ & $1.07(0.82$ to 1.40$)$ & $1.07(0.84$ to 1.36$)$ & $1.09(0.81$ to 1.47$)$ & $1.10(0.87$ to 1.39$)$ \\
\hline Dislike school & $70 / 602(11.6)$ & $143 / 910(15.7)$ & $1.22(0.85$ to 1.76$)$ & 1.2510 .94 to 1.66 & $1.13(0.75$ to 1.69$)$ & $1.29(0.98$ to 1.70$)$ \\
\hline \multicolumn{7}{|c|}{ Believes most peers have sexual intercourse } \\
\hline Like school & $114 / 1938$ (5.9) & $97 / 1664(5.8)$ & 1 & 1 & 1 & 1 \\
\hline Ambivalent & $107 / 1280(8.4)$ & $93 / 1348(6.9)$ & 1.46 (1.08 to 1.97$)$ & $1.20(0.85$ to 1.68$)$ & 1.49 (1.03 to 2.15$)$ & $1.22(0.86$ to 1.73$)$ \\
\hline Dislike school & $85 / 570(14.9)$ & $114 / 914(12.5)$ & 2.80 (2.16 to 3.64$)$ & 2.30 (1.58 to 3.36$)$ & $2.80(2.10$ to 3.72$)$ & 2.07 (1.35 to 3.19$)$ \\
\hline \multicolumn{7}{|c|}{ Expects sexual intercourse by aged $16^{*}$} \\
\hline Like school & $609 / 1495$ (40.7) & $550 / 1363(40.4)$ & 1 & 1 & 1 & 1 \\
\hline Ambivalent & $465 / 924(50.3)$ & $517 / 1055(49.0)$ & 1.52 (1.24 to 1.86$)$ & 1.34 (1.15 to 1.57$)$ & 1.51 (1.18 to 1.91$)$ & 1.31 (1.12 to 1.55$)$ \\
\hline Dislike school & $190 / 367(51.8)$ & $380 / 647(58.7)$ & 1.61 (1.28 to 2.01$)$ & 1.95 (1.51 to 2.52$)$ & $1.68(1.33$ to 2.10$)$ & 1.98 (1.55 to 2.54$)$ \\
\hline \multicolumn{7}{|c|}{ Expects parenthood by aged $20^{*}$} \\
\hline Like school & $284 / 1570(18.1)$ & $375 / 1267(29.6)$ & 1 & 1 & 1 & 1 \\
\hline Ambivalent & $204 / 971(21.0)$ & $258 / 955(27.0)$ & 1.02 (0.94 to 1.55$)$ & $0.88(0.72$ to 1.08$)$ & $1.22(0.90$ to 1.65$)$ & 0.89 (0.72 to 1.03$)$ \\
\hline Dislike school & $162 / 459$ (35.3) & $271 / 692$ (39.2) & 2.47 (1.96 to 3.11$)$ & $1.53(1.25$ to 1.87$)$ & $2.33(1.79$ to 3.04$)$ & 1.41 (1.14 to 1.75$)$ \\
\hline \multicolumn{7}{|c|}{ Drunk once a month or more } \\
\hline Like school & $186 / 2054(9.1)$ & $146 / 1785(8.2)$ & 1 & 1 & 1 & 1 \\
\hline Ambivalent & 188/1387 (13.6) & $181 / 1465$ (12.4) & 1.57 (1.36 to 1.82 ) & 1.58 (1.15 to 2.17$)$ & 1.62 (1.37 to 1.93 ) & 1.63 (1.16 to 2.29$)$ \\
\hline Dislike school & $173 / 632(27.4)$ & $239 / 980(24.4)$ & 3.79 (2.86 to 5.01$)$ & $3.62(2.84$ to 4.62$)$ & 3.79 (2.92 to 4.92$)$ & $3.77(2.81$ to 5.07$)$ \\
\hline \multicolumn{7}{|c|}{ 1 } \\
\hline Like school & $92 / 2101$ (4.4) & $89 / 1828$ (4.9) & 1 & 1 & 1 & 1 \\
\hline Ambivalent & $88 / 1392(6.3)$ & $83 / 1486(5.6)$ & 1.47 (1.11 to 1.95$)$ & $1.15(0.82$ to 1.62$)$ & 1.40 (1.03 to 1.92$)$ & $1.03(0.67$ to 1.61$)$ \\
\hline Dislike school & $96 / 622(15.4)$ & $115 / 988(11.6)$ & 3.99 (2.69 to 5.91$)$ & $2.57(2.07$ to 3.20$)$ & 3.74 (2.40 to 5.81 & 2.44 (1.87 to 3.18$)$ \\
\hline
\end{tabular}


2.44 ( 1.87 to 3.18$)$ ). Dislike of school was also associated with higher confidence regarding condom use (0.77 (0.62 to 0.95$)$, 0.77 (0.64 to 0.92)). Ambivalence towards school was associated with being drunk monthly or more (1.62 (1.37 to 1.93$), 1.63$ (1.16 to 2.29)) and expecting to have sex by aged 16 (1.51 (1.18 to 1.91), 1.31 ( 1.12 to 1.55$)$ ) for girls and boys and believing most peers have sexual intercourse (1.49 (1.03 to 2.15$)$ ) and having sexual intercourse (1.40 (1.03 to 1.92)) for girls but not boys.

Adjusted Wald tests indicated that there were no significant interactions between the effects of socioeconomic status and attitude to school on any of the outcomes.

Adjusting for having had sex did not substantially affect associations concerning knowledge and confidence, and so was not included in multivariate models. Adjusting the measure of low knowledge about contraception and STIs so that this was defined as students having not correctly answered a greater or fewer number of questions (that is, eight rather than seven) made no difference to the patterns of associations found regarding this variable.

\section{DISCUSSION}

Our two dimensions of social exclusion-socioeconomic disadvantage and dislike of school-are both associated with different risk factors for teenage pregnancy. Even in this baseline cross sectional survey it is clear that social inequalities in sexual health risk (measured by a variety of cognitive and behavioural measures) exist among 13 and 14 year olds.

Socioeconomic disadvantage was associated with low knowledge about sex and contraception, but not with expectations of sexual intercourse before age 16. In contrast, dislike of school was not associated with low knowledge, but was associated with expectations about having sex before age 16. Our findings suggest that both exposures might influence the risk of teenage pregnancy, and that dislike of school seems potentially to be particularly important, in that its association with behavioural measures is especially strong.

Because the crude and adjusted ORs are quite similar, inter-confounding is relatively insignificant. We therefore hypothesise that in determining risk of teenage pregnancy, our two dimensions of social exclusion affect somewhat different groups of individuals, and in this sense could be called independent. This possibility is consistent with the qualitative finding of Hughes et al that only some young women from socioeconomically disadvantaged backgrounds have low expectations concerning their careers. It may also be that only some young people who dislike school are socioeconomically disadvantaged (at least according to our measure of housing tenure-see below), but that many such individuals are at increased risk of future teenage pregnancy. This possibility is supported by the only partial overlap between socioeconomic status and dislike of school, indicated in table 2.

We found that those who disliked school did not have lower knowledge levels than those who liked school but none the less were more likely to be or to expect to be sexually active by age 16 , and to expect to be parents by age 20 . From this, we might hypothesise how educational dimensions of social exclusion might operate in increasing the risk of teenage pregnancy. Willis reported that, for some young people, the ethos and values embedded in school resulted in their feeling alienated from it, and adopting attitudes and behaviour that run counter to those promoted in it. ${ }^{16} \mathrm{~A}$ similar process might explain our results, namely that young people who dislike school (that is, are alienated from school) might be more likely to come to see teenage pregnancy as inevitable or as positive alternative to continuing education or a career.
However, we should caution that firm conclusions about causality should be made on the basis of an empirical examination of temporality, ${ }^{17}$ which is not possible in this cross sectional study. It may, for example, be that, rather than alienation from school causing young people to engage in certain behaviours and hold certain views, it is actually engagement with these behaviours and views that increases young people's feelings of disengagement with school. This question will be considered in future research, discussed below.

Furthermore, we cannot be certain about the validity of some of our measures. Regarding our measures of exposure, the greater consistency of associations regarding dislike of school compared with socioeconomic disadvantage might, in large part, reflect the greater proportion of students answering this question. Our measure of housing tenure may not have been highly valid, perhaps because a question on this may be difficult for students to answer. However, our results are broadly in line with the findings of the 1991 UK census, in which $74 \%$ report owner occupation ( $72 \%$ this sample), $18 \%$ renting from local authority (22\% this sample), and $8 \%$ private renting (5\% this sample). ${ }^{18}$ No other individual measures of socioeconomic disadvantage were available, except parental occupation, which had a very poor response rate. Indices of deprivation could not be used, both because of the poor completion of postcode information by respondents, and because these report area, not individual, disadvantage and so would shed no light on the research questions we are exploring. In addition there may be limitations to the conclusions that can be drawn about the relation between satisfaction with school and sexual health outcomes based on the use of a single response about "liking/disliking"school. Further research might be strengthened by developing additional measures to capture other aspects of this multifaceted concept.

Regarding our measures of outcome, while research indicates that cognitive measures (that is, knowledge, confidence, and attitudes) are associated with behavioural measures (such as condom use) among young people, evidence concerning associations between these measures and teenage pregnancy is inconclusive. ${ }^{19}{ }^{20}$ Furthermore, the validity of young people's expectations about sexual initiation and conception in predicting risk of teenage pregnancy has not been researched. Our measure of confidence with proper use of condoms may have indicated different phenomena in boys and girls. While, for boys, it might have indicated confidence about the mechanics of using condoms, for girls, it may have indicated confidence in negotiating condom use. The high rate of "unsure" responses to this question might suggest respondents found the question difficult. A possible lack of validity of our measure of confidence in condom use might explain our findings of inverse associations between both dislike of school and socioeconomic disadvantage and low confidence in using condoms. Alternatively, this finding might suggest that young people who do not perceive teenage pregnancy primarily in terms of negative risk are less inclined to question their skill in using condoms. Existing research does support the validity of alcohol use and early initiation of sex as predictors of teenage pregnancy. ${ }^{17} 2122$ However, we acknowledge that the outcome measures we have used here are imperfect, early indicators of risk of teenage pregnancy, and plan to test the hypotheses developed in this paper in future research in which the key outcome will be teenage pregnancy itself. Such research will be longitudinal, and will therefore examine the extent to which prior educational alienation and later sexual health risk are associated temporally and statistically. Such temporal analysis will add to the evidence regarding causality (see Bradford Hill's criteria $)^{23}$ but will not, on its own, be definitive. 


\section{CONCLUSION}

Social inequalities in various markers of sexual health risk, including early initiation of sexual activity, are apparent among 13 and 14 year olds. We hypothesise that different dimensions of young people's social exclusion may affect future risk of teenage pregnancy in different ways and that alienation from education may be a particularly important dimension of exclusion in the determination of risk of teenage pregnancy. Socially excluded young people may be more likely to become pregnant as teenagers not because of knowledge or confidence deficits but because their alienation from school and more general social exclusion results in their adopting fatalistic or positive attitudes to parenthood in their teenage years. For some young people, having a baby may, in this context, represent a positive and achievable goal. This possibility, if confirmed in later longitudinal analysis would have important implications for teachers and educational and social policy makers in responding to social exclusion among young people in the UK and perhaps elsewhere.

\section{Authors' affiliations}

C P Bonell, V J Strange, A R Oakley, Social Science Research Unit, Institute of Education, University of London, UK

J M Stephenson, A J Copas, S P Forrest, A M Johnson, S Black, Department of Sexually Transmitted Infections, University College London, University of London, UK

Funding: UK Medical Research Council funding for two projects respectively entitled: "Examining socio-economic and cultural determinants of teenage sexual health"; and "A randomized controlled trial of the effectiveness of peer-led sex education in schools".

Conflicts of interest: none declared.

\section{REFERENCES}

1 Golding P. Excluding the poor. London: Child Poverty Action Group, 1986:84.

2 Madanipour A, Cars G, Allen J. Social exclusion in European cities. London: Jessica Kingsley, 1998.
3 Byrne D. Social exclusion. Buckingham: Open University Press, 1999:158.

4 Social Exclusion Unit. Social exclusion unit: What's it all about? http:// www.cabinet-office.gov.uk/seu.

5 Social Exclusion Unit. Teenage pregnancy. London: Cabinet Office, 1999:139.

6 Botting B, Rosato M, Wood R. Teenage mothers and the health of their children. http://www.cabinet-office.gov.uk/seu.

7 Kiernan KE. Teenage motherhood-associated factors and consequencesthe experiences of the British Birth Cohort. Journal of Biosocial Science $1980 ; 12: 393-5$

8 Social Exclusion Unit. Include. http://www.cabinet-office.gov.uk/seu.

9 Dearden K, Hale C, Alvarez J. The educational antecedents of teen fatherhood. British Journal of Educational Psychology 1992;62:139-47.

10 Mott FL, Fondell MM, Hu PN, et al. The determinants of first sex by age 14 in a high-risk adolescent population. Fam Plann Perspect 1996;28:13-18.

11 Paul C, Fitzjohn J, Herbison P, et al. The determinants of sexual intercourse before age 16. J Adolesc Health 2000;27:136-47.

12 Hughes K, Cragg A, Taylor C. Young people's experiences of relationships, sex and early parenthood: qualitative research. London: Health Education Authority, 1999:78

13 Strange V, Forrest S, Oakley $A$, et al. A listening trial: 'qualitative' methods within experimental research. In: Oliver S, Peersman G, eds. Using research for effective health promotion. Buckingham: Open University Press, 2001:138-53.

14 Stephenson JM, Oakley A, Charleston S, et al. Behavioural interventions trials for HIV/STD prevention in schools: are they feasible? Sexually Transmitted Infections 1998;74:405-8.

15 Oakley A, Rajan L. Social class and social support: the same or different? Sociology 1991;25:31-59.

16 Willis P. Learning to labour, how working class kids get working class jobs. Aldershot: Saxon House, 1977:204

17 Gold RS, Karmiiloff-Smith A, Skinner MJ, et al. Situational factors and thought processes associated with unprotected intercourse in heterosexual students. AIDS Care 1992:4:305-23.

18 Boheim R, Taylor M. Residential mobility, housing tenure and the labour market in Britain. Colchester: Instutute for Economic and Social Research/ Institute for Labour Research, 1999:36

19 Abraham C, Sheeran P. Modelling and modifying young heterosexuals' HIV preventative behaviour: a review of theories, findings and educational implications. Patient Education and Counselling 1994;23:173-86.

20 Conner M, Norman P (eds). Predicting health behaviour. Buckingham: Open University Press, 1995:230.

21 Johnson AM, Wadsworth J, Wellings K, et al. Sexual attitudes and lifestyles. Oxford: Blackwell, 1994:499.

22 Wellings K, Nanchahal K, Macdowall W, et al. Sexual behaviour in Britain: early heterosexual experience. Lancet $2001 ; 358$ : 1843-50.

23 Bradford-Hill A. The environment and disease: association or causation? Proceedings of the Royal Society of Medicine 1966;58:295. 